doi $\frac{\text { https://periodicos.ufpa.br/index.php/revistam }}{\mathrm{http} / / \text { dx.doi.org/10.18542/rmi.v15i24.10104 }}$ Margens: Revista Interdisciplinar | e-ISSN:1982-5374 | V. 15 | N. 24 | Jun, 2021, pp, 153-163.

\title{
TIADOZIA DA ROCHA POR "ENGANAR" O JUIZ, PERDE SUAS TERRAS - O GÊNERO E O SISTEMA SESMARIAL NA CAPITANIA DO SIARÁ GRANDE
}

\author{
TIADOZIA DA ROCHA FOR “CHEATING” THE JUDGE, LOSES HIS LAND - GENDER AND THE \\ SESMARIAL SYSTEM IN THE CAPITANIA OF SIARÁ GRANDE
}

\section{Leiliane Kecia MAGALHÃES (UFC) $)^{1}(\mathbf{\theta}$}

\begin{abstract}
Resumo: Este artigo analisa a solicitação de terras realizado em 1706 por Tiadozia da Rocha à Coroa portuguesa na capitania do Siará Grande, a fim de conferir a probidade dos pedidos formulados não só por homens como também por mulheres, pois não existe um mundo composto por um único tipo de sujeito, mas por uma diversidade de sujeitos em relações de poder, como avalia os estudos de Gênero. A partir da catalogação dos documentos oficiais relacionados a política de doação de terras, a saber as Cartas de Sesmarias e o conjunto de leis do Sistema Sesmarial, verificou-se que apesar do controle da administração portuguesa, tanto mulheres como homens se utilizaram de meios ilícitos em seus requerimentos atendendo seus próprios interesses em oposição aos do Rei, no intuito de tornarem-se grandes senhoras e senhores de terras
\end{abstract}

Palavras-chave: Capitania do Siará Grande. Gênero sistema sesmarial.

\begin{abstract}
This article analyzes a request for land made in 1706 by Tiadozia da Rocha to the Portuguese Crown in the captaincy of Siará Grande, to verify the probity of requests made not only by men but also by women, as there is no world composed of a single type of subject, but due to the diversity of subjects in power relations, as evaluated in gender studies. From the cataloging of official documents related to the land donation policy, namely the Letters of Samaria's and the set of laws of the Sesmarial System, it was found that despite the control of the Portuguese administration, both women and men used illicit means in their requests serving their own interests in opposition to the Kings, to become great ladies and lords of land.
\end{abstract}

Keywords: Captaincy of Siará Grande. Gender sesmarial system.

\footnotetext{
${ }^{1}$ Mestranda em História Social, pelo Programa de Pós-Graduação em História (PPGH) pela Universidade Federal do Ceará (UFC). É professora da Escola de Ensino Médio de Amontada. Tem experiência na área de História, com ênfase em História do Brasil. E-mail: leilikecia@gmail.com
} 


\section{INTRODUÇÃO}

A legislação portuguesa determinava que as terras da colônia, denominadas de sesmarias, só poderiam ser adquiridas pelo instrumento jurídico da doação do Rei, mediante a justificativa de tornálas produtivas para o Reino, mas nem todos tiveram acesso a essas doações, existia todo um processo burocrático a ser seguido, resultando em conflitos entre os colonos, chamados de sesmeiros e a administração lusa.

O enfrentamento as autoridades portuguesas nem sempre acontecia de forma explícita, ações como burlar as leis, enganar os representantes régios, são enfrentamentos que embora implícitos buscavam atender os interesses individuais em detrimento dos interesses da monarquia, especialmente quando se tratava da obtenção de terras, pois além do seu valor econômico, ser senhor e senhora de terras também significava ser senhor e senhora de gentes.

Esse poderio variava de acordo com a extensão de terra adquirida, pois quanto maior a área, maior seria o número de pessoas que dependeriam desse senhor ou senhora de terras, entretanto a política portuguesa tinha como objetivo o aproveitamento da terra para lucratividade do reino, não sendo do seu interesse a distribuição de grandes extensões de terras a um único indivíduo, pois este poderia não ter condições de torná-la produtiva em toda sua extensão. Diante de interesses opostos, mulheres e homens usaram de estratégias para sublevar os objetivos do Rei e alcançar os seus próprios interesses, como foi verificado na análise das Cartas de Sesmarias, documentos pelos quais as solicitações eram realizadas.

Mulheres solicitando terras e infringindo leis em prol dos seus próprios interesses destoa da imagem que se tem da mulher colonial, como explica Mary Del Priore (1997, p. 11):

A mulher na história do Brasil tem surgido recorrentemente sob luz de estereótipos, dando-nos enfadada ilusão de imobilidade. Auto-sacrificada, submissa sexual e materialmente e reclusa com rigor, à imagem da mulher de elite opõem-se a promiscuidade e a lascívia da mulher de classe subalterna [...]. Para romper com a silenciosa paisagem dos estereótipos femininos, fundada na negação dos papéis históricos representados por mulheres, faz-se necessário rastrear a informação mais humilde, adivinhar a imagem mais apagada e reexaminar o discurso mais repetitivo. Só assim podemos libertar as imagens femininas do olhar que só as vê contraditórias, pois pensar o "por que" e "para o quê" de uma história da mulher brasileira significa abandonar as polarizações, e deixar emergir a memória de tensões entre os papéis masculinos e femininos.

Com a finalidade de romper o silenciamento sobre a ação de mulheres nos estudos econômicos no período colonial, especialmente nas capitanias do Norte, e corroborar com a 
desconstrução desses estereótipos, iniciou-se a pesquisa sobre as mulheres que solicitaram terras na capitania do Siará Grande, no curso de graduação, ganhando continuidade no mestrado em História Social pela Universidade Federal do Ceará (UFC). As fontes consultadas foram as Cartas de Sesmarias referentes a capitania do Siará Grande e as leis que configuravam o Sistema Sesmarial.

Das 1449 Cartas de Sesmarias, selecionou-se as Cartas solicitadas por mulheres e as que possuíam alguma relação com as mesmas. Seguiu-se a organização dos dados em planilhas, identificando o nome das solicitantes, a extensão das terras solicitadas e as concedidas, a justificativa e o número de terras obtidas por cada solicitante. Foram mais de duzentas Cartas de Sesmarias catalogadas, das quais uma chamou a atenção por trazer textualmente os conflitos existentes entre a administração portuguesa e as senhoras e senhores de terras e as estratégias utilizadas para obtenção de terras, temática a qual se detém esse artigo.

A Carta de Sesmaria em questão pertencia a Tiadozia da Rocha em conjunto com Pedro Gonçalves de Carvalho, localizada no rio Banabuiu, solicitada em 11 de setembro de 1706, concedida pelo Capitão mor Gabriel da Silva do Lago, com a extensão de 3 léguas de terras para cada solicitante. A partir dessa Carta constatou-se que tanto homens quanto mulheres utilizaram de estratégias para alcançar mais terras do que a lei estabelecia.

\section{O GÊNERO E O SISTEMA SESMARIAL}

O Sistema Sesmarial, de acordo com Lígia Maria Osorio Silva (1996, p.37) "correspondeu à ordenação jurídica da apropriação territorial que a metrópole impôs à colônia enquanto durou o seu domínio sobre ela", prescrito nas Ordenações do Reino e complementado por forais e alvarás ao longo do tempo, o qual determinava que a terra poderia ser doada a qualquer pessoa, contanto que fosse cristã, a legislação não fazia nenhuma restrição para além da religião, uma vez que o objetivo primordial da doação de terras era torná-las produtivas para a Coroa portuguesa, como estabelece o Código Filipino:

as pessoas a que assi forem dadas as sesmarias, as não aproveitarem ao tempo que lhes for assinamos, ou no tempo que nesta Ordenação lhes assinamos, quando expressamente lhes não fôr assinado, façam logo os Sesmeiros executar as penas que lhes forem postas, e dêm as terras que não stiverem aproveitadas, a outros que a aproveitam. (Livro $4^{\circ}$, Título XLIII, 2004, p.824) ${ }^{2}$

\footnotetext{
${ }^{2}$ Optou-se em manter a grafia original do documento.
} 
Desse modo, se as terras não fossem aproveitadas no tempo determinado, dar-se-ia a outros, portanto se uma mulher conseguisse provar que seria capaz de tornar a terra produtiva, não haveria impedimento legal. Contudo, apesar do Sistema Sesmarial não ter limitado as doações a um único sexo, o número de mulheres que se tornaram senhoras de terras na capitania do Siará Grande não chegou nem a um terço do total, o que evidencia a existência de outros condicionantes para a obtenção de terras, além do que estava prescrito na lei, pois como bem esclarece Mary Del Priore (1997, p.13):

Melhor do que tentar responder se as mulheres tinham poder, é tentar decodificar que poderes e estratégias elas detinham por trás da ficção do poder masculino, e como se articulavam a sua subordinação e resistência. O estudo dos discursos normativos sobre a mulher deve ser estimulado quando levar em conta as práticas sociais, do contrário, tendo no homem o sujeito das falas, e a mulher seu objeto, corre-se o risco de fazer um retrato fora de foco do segmento feminino. Vale dizer, finalmente, que o território feminino na história não é um lugar sereno, onde a mulher se locomove sem riscos, e onde o confronto e o conflito não imprimam suas marcas. A história da mulher é, antes de tudo, uma história de complementaridades sexuais, onde se interpenetram práticas sociais, discursos e representações do universo feminino como uma trama, intriga e teia.

Por concordar com essas complementaridades, solidariedades e conflitos, experimentadas pelos sujeitos históricos, a presente pesquisa faz uso da categoria Gênero pois estudar as mulheres isoladamente reforçaria o mito de que um sexo muito pouco ou nada tem a ver com o outro sexo, uma vez que as informações sobre as mulheres são necessariamente informações sobre os homens, um implica o estudo do outro, pois o mundo das mulheres faz parte do mundo dos homens.

Ao abordar qualquer tema de Gênero, necessariamente observa-se uma interação de poderes, nessa perspectiva o objeto de investigação não seria exclusivamente a mulher, mas sim sua relação com os homens e com outras mulheres, pois como afirma Guacira Lopes Louro (2003, p. 33): "não existe a mulher, mas várias e diferentes mulheres que não são idênticas entre si, que podem ou não ser solidárias, cúmplices ou opositoras", sem confundir dessa maneira os "estudos de gênero" aos “estudos sobre mulher" pois apesar de compartilharem vários pressupostos buscam superar alguns outros, como a visão de uma mulher sempre subordinada ou sempre subversiva, pois que um mesmo sujeito pode vivenciar as duas condições dentro do mesmo contexto.

Essa complexidade de relações de poder foi observada de forma significativa em todo o processo de doação de terras, uma vez que a Carta de Sesmaria era apenas o passo inicial de um longo percurso burocrático, Costa Porto (1965) descreveu as etapas a serem realizadas para a obtenção de terras de acordo com o Sistema Sesmarial: da solicitação passava-se ao ato de registrar, por conseguinte a confirmação do Rei, o pagamento de um foro e, uma das principais dificuldades 
encontradas pela administração portuguesa - a demarcação das terras. Todas essas etapas exigiam um certo conhecimento legal e geravam gastos para o solicitante, além da manutenção de boas relações com os agentes responsáveis por cada etapa dessa concessão.

Com a quantificação dos dados verificou-se que a maioria das solicitações eram realizadas por um grupo de indivíduos, cuja composição poderia ser: homens e homens, mulheres e homens, mulheres e mulheres. Os pedidos realizados individualmente eram a exceção, mais uma evidência da importância das relações entre os indivíduos, interligados por interesses comuns, uma vez que a solidariedade entre sujeitos era essencial para sobrevivência dos mesmos naquele contexto de ocupação.

Na capitania do Siará Grande foram 217 pedidos realizados com a presença de mulheres, dos quais 17 foram compostos por grupo só de mulheres, 36 apenas por uma única mulher e 164 realizados em grupos formados por mulheres e homens. Esses dados indicam que os pedidos de mulheres em companhia de homens tinham mais probabilidade de serem atendidos, nessas circunstâncias aliar-se a um homem seria mais vantajoso para que seus interesses fossem alcançados.

A pesquisa averiguou que esses homens possuíam algum vínculo familiar com as mesmas, eram pais, irmãos, avôs, esposos, genros, entre outros, vale destacar que o parentesco entre os solicitantes nem sempre vinha descrito na Carta, por vezes se fez necessário consultar outras fontes para identificá-los. Sobre Tiadozia da Rocha e Pedro Gonçalves de Carvalho, as fontes não possibilitaram dizer se existia algum vínculo entre eles, no entanto há uma possibilidade de parentesco de Pedro com o escrivão responsável pelas Cartas de Sesmaria daquele ano, o que poderia ter facilitado o acesso de Tiadozia da Rocha aos trâmites burocráticos referentes a aquisição das terras.

Desse modo, a aliança entre mulheres e homens na obtenção de terras na capitania do Siará Grande demonstram como as relações de poder são dinâmicas, onde o contexto de dominação por vezes abria espaço para relações de reciprocidade, como se vê na Carta de Sesmaria solicitada por Tiadozia da Rocha e Pedro Gonçalves de Carvalho.

\section{TIADOZIA DA ROCHA: A AÇÃO DE ENGANAR A ADMINISTRAÇÃO LUSA}

As solicitações de terras eram realizadas por escrito e expedidas pelo Capitão mor, contendo o nome do requerente, o lugar de sua moradia, a localização geográfica da terra solicitada e a justificativa da solicitação, como se vê no trecho da Carta de Sesmaria de Tiadozia da Rocha: 
Sor Cappitam Mor dizem Tiadozia da rocha E pedro goncalves de carvalho Moradores nesta Capitania dosiara rande que elles suplicantes tem gados Vaquems eCavalares E msid Cirasois enão tem terras pera os poderem Cirar Etem notiçia que em as testadas do tinente Manoel pintto da rocha pello bonabuhu asima ha terras devolutas edezaproveitadas as Coais foram pedidas a Vera Vinte etres annos ahuns homen Moradores em o rio S. frc. ${ }^{\circ}$ os Coais homens nunqua tiveram gados nesta Capitania nem nunqua Virão aella pera os poderem asituar oque the o prezente não tem feito portanto $\mathrm{P}$ Avmce seja servido comsederlhe em nome desua Magestade que deus agrade acada hum delles suplicantes tres Legoas deterra de Comprido pelo dito rio bonabuhu asima visto ser sim na mesma forma que se concedeo antigamentes A Manoel teixeira Eseus Companheiros os Coais athe oprezente não pouvoaram E elles suplicantes as querem povoar com seus gados emais Cirasois pera aumento dafazenda Rial. (APEC, p. 47) ${ }^{3}$

A solicitação em sua forma estava correta, as terras estavam verdadeiramente desocupadas e mediam seis léguas, três para cada suplicante, como era exigia por lei, o objetivo estava correto, aumentar a fazenda do Rei, contudo na informação acerca da residência, ao dizer que eram moradores da capitania do Siará Grande, o desembargador averiguou que se tratava de uma inverdade, pois um dos solicitantes Pedro Gonçalves de Carvalho na realidade era morador de Lisboa, fato que resultou num processo contra os solicitantes.

O desembargador era Cristóvão Soares Reimão, nomeado em 1703 para averiguar as terras da capitania, tendo seu trabalho iniciado em 1706, tendo um comportamento exemplar, como destaca Antonio (Antônio) Bezerra (1986, p. 245): “A integridade e independência com que se houve sempre no desempenho das comissões que lhe foram confiadas, fizeram-no desagradar a interessados poderosos, e daí as lutas que teve de sustentar contra os que pretendiam domar a severidade da justiça."

O desagrado desses poderosos foi resultado da fiscalização realizada pelo desembargador, onde muitas terras foram devolvidas ao Rei por terem sido obtidas de forma irregular, alguns desses poderosos chegaram a pegar em armas contra Cristóvão Soares Reimão, a fim de impedir a averiguação de suas solicitações, como analisa Lígia Maria Osorio Silva (1996, p. 50):

A aplicação dessas normas não foi de todo modo tranquila. Preocupada com a ocupação da colônia e entusiasmada com a riqueza gerada pelo açúcar, a metrópole tivera uma política de liberalidade em relação ao tamanho das propriedades até fins do século XVII e não se preocupara muito em ver as condições das concessões cumpridas. Quando a partir desta época quis mudar sua atitude em relação à terra, foi natural que esbarrasse na resistência dos colonos.

${ }^{3}$ Optou-se em manter a grafia original do documento. 
A pena aplicada diante das irregularidades das solicitações de terras, era a perda parcial ou completa das terras doadas como aconteceu com Tiadozia da Rocha, a qual dentre as Cartas de Sesmarias analisadas chamou atenção pelos desdobramentos que a sua solicitação provocou, pois teve seu nome citado em outras duas Cartas de Sesmarias, a primeira sendo do capitão Manoel da Rocha e o capitão Nicolau Lopes Fiuza e a segunda do capitão Lazaro Gomes de Almeida e o tenentecoronel Estevão de Sousa Palhano.

$\mathrm{Na}$ Carta de Sesmaria desses homens, estava expresso que os solicitantes requeriam as mesmas terras que outrora haviam sido doadas a Tiadozia da Rocha e Pedro Goncalves de Carvalho, uma vez que:

desta data foi excluida della a suplicada por emganar ao juis prevativo das sismarias por pedir com outro companheiro morador em Lisboa e o nam ser nesta capitania com q mandou o juis prevativo que nam trazendo o seu sócio citado a suplicada a Pdro Glz errêo com a suplicada na dita data a tempo de tres mezes fose espulcada hum e outro [...]. (APEC, p. 25)

O escrivão foi taxativo ao utilizar o termo "enganar", pois Tiadozia da Rocha havia dito na Carta de Sesmaria que tanto ela quanto Pedro Goncalves de Carvalho eram moradores da capitania do Siará Grande, quando na verdade ele morava em Portugal, sendo que o desembargador ainda concedeu um prazo de três meses para que Pedro Goncalves de Carvalho se apresentasse e ocupasse as terras solicitadas, o que não ocorreu. Essa inverdade é um indicativo de que Tiadozia da Rocha queria obter uma extensão de terras maior do que o limite de três léguas estabelecido pela legislação, pois se Pedro não viria ocupar as três léguas que lhe cabia por morar em Portugal, essas ficariam com Tiadozia, perfazendo um total de seis léguas, o dobro de terras que era permitido por pessoa.

Ao ser descoberto o "engano", as terras doadas a Tiadozia e a Pedro retornaram ao domínio do Rei, podendo ser novamente doadas, fato que ocorreu em 1707, um ano após Tiadozia da Rocha ter feito sua solicitação. É curioso notar que os quatro sesmeiros que pediram as terras que haviam sido excluídas de Tiadozia da Rocha e Pedro Goncalves de Carvalho, já haviam pedido terras com familiares de Tiadozia, seria esta uma nova estratégia para recuperar as terras perdidas para o mesmo grupo parental.

A Carta de Sesmaria de Tiadozia da Rocha é significativa para compreender a resistência de homens e mulheres da capitania do Siará Grande ao domínio régio, pois os desdobramentos que essa solicitação ocasionou revela que a leitura de forma individual desse documento incorreria no erro da

\footnotetext{
${ }^{4}$ Optou-se em manter a grafia original do documento.
} 
passividade das mulheres e dos homens dentro do sistema colonial, mas ao comparar com outras Cartas identificou-se formas diversas de resistir a essa política, embora nem sempre bem-sucedida como foi o caso de Tiadozia.

Há de se mencionar que o desembargador também não teve sucesso no exercício do seu trabalho, Patrícia de Oliveira Dias (2016), em sua pesquisa sobre as sesmarias fiscalizadas pelo desembargador Cristóvão Soares Reimão no Siará Grande, computou os seguintes dados: das 11 sesmarias averiguadas, 06 delas possuíam léguas a mais do que o permitido por lei, 02 possuíam informações falsas sobre o local de nascimento dos sesmeiros, 02 não foram povoadas no tempo determinado e 01 possuía léguas a menos do que fora estipulado pela Coroa e, que após 1708 não encontrou mais nenhum relato sobre outras verificações, provavelmente estagnadas após o grupo de potentados locais pegar em armas com o fim de parar a fiscalização.

O desembargador enviou cartas ao Rei relatando as dificuldades encontradas na execução do seu trabalho, que não tivera apoio nem mesmo do Capitão mor da capitania e se via numa situação conflitante com os poderosos da região. A resposta da administração portuguesa as suas reclamações não foi o que ele esperava, pois medir e demarcar terras nos distantes sertões onde a presença da justiça régia era diminuta ou inexistente, acabava por impedir uma ação mais enérgica da Coroa, que de acordo com Rafael Ricarte da Silva (2016) era um espaço onde imperava a lei da negociação ou a regra dos conquistadores.

Na Carta régia de 24 de janeiro de 1711, o desembargador é dispensado de continuar o serviço de medição das terras do Rio Grande e do Siará Grande por motivo de doença, segundo o Barão de Studart (1985) o objetivo do Rei era acalmar os ânimos dos solicitantes de terras, exaltados pela possibilidade de perderem não só um bem de valor econômico, mas que também lhes conferia poder político e social, como explica Márcia Maria Mendes Motta (1998, p.39):

A luta pela terra expressava, em suma, não somente a possibilidade de obter o domínio sobre a mesma, mas também sobre os homens que ali habitavam ou desejavam habitar. Nesse sentido, resistiam em medir e demarcar suas terras porque tal limitação territorial implicava um limite ao exercício de seu poder sobre vizinhos e posseiros e uma subordinação ao poder externo, representado pela Coroa. Ser senhor de terras significava antes de mais nada, ser senhor - e era sobretudo este domínio senhorial que não podia ser medido ou limitado.

Para os fazendeiros, a questão não se colocava em termos de acesso à terra, mas sim a dimensão do poder que eles viriam a exercer sobre quem não a detinha. A existência de matas virgens significava a possibilidade de extensão deste poder: o fazendeiro ou uma ampla camada de lavradores poderiam vir a ocupá-las, permitindo a consolidação de pequenos posseiros também ansiosos por assegurar e legitimar de algum modo a posse de suas terras. Para o fazendeiro, portanto, disputar uma nesga, uma desprezível fatia de terra significava resguardar seu poder, impedir que terceiros 
viessem a reivindicar direitos sobre coisas e pessoas que deviam permanecer, de fato ou potencialmente, sob seu domínio.

Perder o poderio sobre terras e gentes não era uma possibilidade aceitável, e quando os enfrentamentos implícitos não eram mais capazes de atender os interesses dos colonos, o pegar em armas se tornava uma opção. A Coroa portuguesa diante da dificuldade de manter a ordem nas capitanias distantes dos centros políticos recuava, enquanto seus súditos ampliavam seus territórios para além do que era lícito. Assim mulheres e homens continuaram a utilizar estratégias para burlar a legislação por todo o período colonial, com o objetivo não de aumentar a fazenda do Rei como escreviam nas Cartas de Sesmarias, mas sim de ampliarem a extensão de suas terras e, por conseguinte suas rendas e seu poder.

\section{CONSIDERAÇÕES FINAIS}

No Siará Grande, apesar das mulheres e homens se mostrarem preocupados com o bem-estar da Coroa portuguesa ao justificarem em suas Cartas de Sesmarias que queriam aumentar os bens do Rei, na verdade buscavam seus próprios interesses se utilizando de estratégias ilícitas para obter grandes extensões de terras, contradizendo as normativas do Sistema Sesmarial e por conseguinte a vontade régia.

Por isso, é preciso estar atento a multiplicidade de experiências entre mulheres e homens, entre mulheres e mulheres, para além do binômio dominação e vitimização, reconhecendo não só os conflitos, como as redes de solidariedades, que variam não só em nível de gênero, como posição social e cor.

É dentro desses conflitos e solidariedades, que as mulheres se fizeram presente no contexto econômico e social da capitania do Siará Grande. Na sua crítica sobre a ausência do sujeito nos estudos históricos, dirigida a Althusser, Edward Thompson (1981, p. 182), explica:

\footnotetext{
"experiência humana". É esse, exatamente, o termo que Althusser e seus seguidores desejam expulsar, sob injúrias, do clube do pensamento, com o nome de "empirismo". Os homens e mulheres também retornam como sujeitos, dentro deste termo - não como sujeitos autônomos, "indivíduos livres", mas como pessoas que experimentaram suas situações e relações produtivas determinadas como necessidades e interesses e como antagonismos, e em seguida "tratam" essa experiência em sua consciência e sua cultura (as duas outras expressões excluídas pela prática teórica) das mais complexas maneiras (sim, "relativamente autônomas") e em seguida (muitas vezes, mas nem sempre, através das estruturas de classe resultantes) agem, por sua vez, sobre sua situação determinada.
} 
A experiência de Tiadozia da Rocha demonstra que diferente da visão estereotipada de uma mulher colonial reclusa, esta não só solicitou terras na capitania do Siará Grande ao Rei, como ainda usou de "engano" para a obtenção de mais léguas do que era permitido pela lei, alegando que havia um homem também interessado em ocupar as terras, quando na verdade este morava em Portugal.

Nas Cartas de Sesmarias analisadas, Tiadozia da Rocha foi apenas uma das mulheres que tentaram obter grandes extensões de terras na capitania do Siará Grande, o que a diferencia das demais é que sua estratégia de burlar a lei não logrou êxito, perdendo de forma integral as terras já obtidas, enquanto outras mulheres foram bem-sucedidas, como Maria da Costa que conseguiu obter 12 léguas de terras ao utilizar a estratégia de se aliar com um padre na realização do pedido.

A ação de mulheres na busca dos seus próprios interesses, utilizando de estratégias escusas como enganar o representante do Rei, demonstram que não existia apenas um padrão de mulher no período colonial, mas múltiplas experiências, as quais apesar de esparsas nos documentos oficiais podem ser identificadas a partir de uma leitura atenta das fontes.

\section{REFERÊNCIAS}

APEC - Datas de Sesmarias do Ceará e índices das datas de sesmarias: digitalização dos volumes editados nos anos de 1920 e 1928. Data de sesmaria, vol. 3, p. 47. (Qual é o ano de publicação?)

Datas de Sesmarias do Ceará e índices das datas de sesmarias: digitalização dos volumes editados nos anos de 1920 e 1928. Data de sesmaria, vol. 5, p. 25. (Qual é o ano de publicação?)

ARAUJO, F. Sadoc de. Cronologia sobralense. Fortaleza: Gráfica Editorial Cearense, 1974-1990.

BEZERRA, Antônio. Algumas origens do Ceará. Edição fac-similada. Fortaleza: Instituto do Ceará, 1986.

DEL PRIORE, Mary. História das mulheres no Brasil. 4.ed. São Paulo: Contexto, 1997.

DIAS, Patrícia de Oliveira. O demarcador de terras: atuação do desembargador Cristóvão Soares Reimão no processo de demarcação de sesmarias na ribeira do Jaguaribe (Capitania do Ceará - Brasil) (1700-1710). Revista de História da UEG - Porangatu, v.5, n.2, p. 86-109. ago./dez. 2016. Disponível em: https://core.ac.uk/download/pdf/230329658.pdf. Acesso em: 15 de fevereiro de 2021.

LOURO, Guacira Lopes. Gênero, sexualidade e educação. Uma perspectiva pós-estruturalista. 6. ed. Petrópolis, RJ: Vozes, 2003.

MOTTA, Márcia Maria Mendes. Nas Fronteiras do poder: conflito de terra e direito à terra no Brasil do século XIX. Rio de Janeiro: Vício de Leitura: Arquivo Público do estado do Rio de Janeiro. 1998. 
ORDENAÇÕES FILIPINAS LIVRO 4º, Título XLIII. Edições do Senado Federal. Brasília, 2004. p. 824.

PORTO, Costa. Estudo sobre o sistema sesmarial. Recife: Imprensa Universitária-UFPE, 1965.

SILVA, Lígia Maria Osorio. Terras devolutas e latifúndio: efeitos da Lei de 1850. Campinas: Ed. da UNICAMP, 1996.

SILVA, Rafael Ricarte da. A capitania do Siará Grande nas dinâmicas do império português: política sesmarial, guerra justa e formação de uma elite conquistadora (1679-1720). 2016. 264f. Tese (Doutorado) - Universidade Federal do Ceará, Programa de Pós-graduação em História Social, Fortaleza (CE), 2016. p. $213-225$

STUDART. Barão de. Datas para a História do Ceará na primeira metade do século XVIII. Revista do Instituto do Ceará, Fortaleza, tomo 09, pp. 86-132, 1895.

THOMPSON, Edward P. A miséria da Teoria ou um planetário de erros: uma crítica ao pensamento de Althusser. Rio de Janeiro: Zahar, 1981. 